\title{
Interpretation of Law and Judges Communities
}

\author{
Marek Zirk-Sadowski
}

Published online: 26 October 2011

(C) The Author(s) 2011. This article is published with open access at Springerlink.com

\begin{abstract}
The principle of omnia sunt interpretanda refers to the derivational conception and derivational theory of interpretation. The principle appears in disputes concerning the role of a judge in the process of interpretation, and this has produced an effect that Polish theory of law is currently getting closer to the conceptions presented in the American debate on activism and textualism. In the practice of jurisdiction, the principle of omnia sunt interpretanda is mostly invoked outside theoretical context. It becomes a manifestation of a new dimension of judicial independence, namely an independent authority over the meaning of legal text. In the following paper the legal cultures and legal theories involved in the dispute are being disclosed in order to put in question the possibility of achieving a clear result of interpretation against a background of a crisis of the relations between law and law-making state, which manifests itself in the peculiar process of legal institutions becoming autonomous in relation to state institutions. In this context, the aforementioned principle constitutes the manifestation of the way in which courts come up with a new definition of the role of the third (sui generic) power. The certain organizational requirements placed upon the courts (especially the SAC and provincial administrative courts) are being scrutinized in order to find out in which mode it is possible to at least reduce the degree of inconsistency of the results of interpretation. Here, the attempt to organize a community of judges for the activities of legal interpretation undertaken by them plays a crucial role.
\end{abstract}

Keywords General theory of interpretation - Derivational conception of interpretation - Court judicature - An interpretative canon of omnia sunt interpretanda. The so-called indeterminacy of judicial decisions . Community of judges

M. Zirk-Sadowski $(\bowtie)$

Chair of Theory and Philosophy of Law, Department of Law and Administration,

University of Łódź, Łódź, Poland

e-mail: msadowski@wpia.uni.lodz.pl 
1. The core of contemporary discussions in the Polish theory of law constitutes the issue of so-called plain meaning of the legal text. It has been introduced to the theory of law as a part of the so-called clarificatory theory of interpretation, created by Professor Jerzy Wróblewski and it has become a subject of controversy since the moment when neopragmatic concepts of natural language - which negate the phenomenon of plain linguistic meaning-have been spread in the Polish theory of law.

According to Wróblewski, only if a clarity of the legal text is doubtful judges have a permission to do the interpretation. The primary thesis of Wróblewski's program accented the interpretative principle of clara non sunt interpretanda. Thanks to the increasing influence of derivational theory of interpretation, created by professor Maciej Zieliński, who was the first to apply the thesis of "omnipresence" of law interpretation in judicial law application, it is more often suggested in judicial justifications to replace the principle of clara non sunt interpretanda with an interpretative canon of omnia sunt interpretanda.

The above dispute is reflected in court judicature. It is increasingly recognized that judicial law application is always accompanied by interpretation of law and in this sense there is no clearly understandable legal text.

What merits noting is the resolution of the judges of the Criminal Chamber of the Supreme Court of 20 January 2005 (I KZP 28/04, OSNKW 2005/1/1), which presented the thesis that even in criminal cases "unmistakable grammatical and semantic clarity (...) does not preclude consideration of rationality and functionality of the application scope set out in that provision...". Similarly, the decision of the Constitutional Court of 13 January 2005 (P 15/02, OTK-A 2005/1/4) posed the thesis that acts of interpretation should be undertaken at any time, even in cases which seemingly do not arouse any interpretative doubts [5].

It turned out that the argument about the obligation to interpret every legal text was on the basis of practice and in numerous theoretical works separated from its source, namely from a derivational conception of interpretation. Currently, the formula of omnia sunt interpretanda is independently invoked as one of interpretative directives, which leads to a peculiar confusion-as it seemsunintended by the creator of derivational conception.

It could be postulated that the principle of omnia sunt interpretanda requires a response of an interpreter, consisting in the application of the principles, guidance and advice contained in derivational conception of legal interpretation [9]. Meanwhile, the demand of interpretation, as a general and indefinite duty, has been assimilated by interpreters taking different assumptions about the nature of the interpretation or having no conception of interpretation at all. The consequences of applying such general duty of interpretation are often erroneously attributed to derivational conception. In other words, the principle of omnia sunt interpretanda acts as a formula for multiple conceptions of legal interpretation which have little or nothing in common with derivational conception. 
2. The continental tradition, which draws both upon legal positivism as well as upon various forms of its criticism, recognizes that the essence of adjudication, however, is the search for a normative sense through law, although this search is differently presented. Ultimately, therefore, legal norm and, more broadly speaking, normative importance, constitutes the result of adjudication and it is ultimately a manifestation of judicial power. Despite the differences within this tradition, it is sometimes jointly referred to-especially in American literature - as an orthodox approach to adjudication and it is commonly considered a part of typically European philosophical tradition [6: 1,7]. What is being presented as an opposition to the latter are the so-called 'heretical' theories of adjudication, represented primarily by the American Critical Legal Studies, which state that these are the judges themselvesrather than the norms - that adjudicate the cases [6: 7]. By means of the latter, judges legitimize the actual manifestations of their political power. The rule of law is the mechanism that serves the purpose of negating social contradictions, so as to enable the continuation of certain-oppressive, in facthierarchies in human relations [4]. Finally, in the so-called 'heretical' views on adjudication, norms only seemingly impose a judgement which is in fact indeterminate by law. What triggers off similar effects are theses of other postmodern trends which recognize that texts do not have meaning which would not constitute the result of structures that hide violence [11].

The followers of the principle of omnia sunt interpretanda, not relativized to any theory of interpretation, cannot be attributed the support for the so-called indeterminacy thesis. They assume that it is the norm that determines judicial adjudication and the dispute at issue relates to the question of what understanding of the norm is correct. The polemic with such recognition of the interpretative obligation falls within the traditional liberal jurisprudence, declaring invalid the thesis that if there is no "direct understanding" and if there is no initial situation, the interpretations of the law can be considered as legitimated, or as equally rational.

3. Until recently, both the practice and a considerable part of theory of law was based on Kazimierz Ajdukiewicz's conception which-according to Jerzy Wróblewski-contains the thesis about the existence of a direct understanding of the legal text. The Polish theory of law is currently getting closer to the conceptions presented in the American debate on activism and textualism.

What has become very influential in Poland was neopragmatics and the views of Stanley Fish, who rejects the existence of direct meaning of the text. Its obviousness is merely an illusion, created from a social perspective or from our position in life. In fact, social life can be understood as a mutual creation of symbols and meanings. Therefore, one cannot be deluded that we will be able to develop any direct linguistic meanings of legal texts. Moreover, language itself is active vis-à-vis reality. It is not the case that the linguistic expressions are simply "applied" to reality. It is rather the manner in which we use them that affects our perception of reality. By means of learning one's mother tongue we learn to perceive reality differently than people of other 
cultures. If the latter is the case, the so-called "clear" meaning of the text in a linguistic sense, is neither clear nor obvious.

The above is suggested by the opponents of a linguistic interpretation, for which-in their opinion - there are no real basis. According to them, we at once enter the sphere of functional interpretation, because we start with a decision that for a given community it is advisable to adopt some conventional linguistic meaning. It can be therefore seen that there is no room in these conceptions for intersubjectively reproducible procedure for interpretation.

4. The exercising of omnia sunt interpretanda without relating it to a specific theory of interpretation is usually merely the sign of a crisis of faith in the possibility of achieving a clear result of interpretation. The effects of using this principle without relativizing it to a particular theory of interpretation seem to be entirely destructive. After finding the need of interpretation, the interpreter does not have any interpretative procedure to offer. Ultimately, it is difficult to re-apply the outcome of interpretation in similar cases. There appears the phenomenon of excessive interpretation, of "zigzag" jurisdiction and frequent, poorly justified changes of interpretative precedents.

The only positive postulate declared in interpretative discourse which applies this principle is the guideline of using a complex interpretation. Such comprehensive approach to interpretation, however, is basically a process in which linguistic importance is presented dynamically. It always emerges from the discussion, for which the legal text constitutes just a basis of considerations. The entire outcome of this discussion has to be ultimately referred to this text and it has to be justified by means of the latter. We know that there is no deductive transition between the legal text and the result of interpretation. Since this is the domain of practical reason, we apply different argumentations here. Legal interpretative discourse turns out to be merely a special case of practical discourse. Interpretation of law is presented in these approaches as a process of argumentation in favour of adopting a specific meaning of legal text. Legal interpretative procedure is at most a special case of legal argumentation.

In the practice of jurisdiction, the principle of omnia sunt interpretanda is mostly invoked outside theoretical context. The effect of the latter is that people participating in court proceedings get the impression of authoritarianism of the judiciary, and they even believe that they are subject to "judicial linguistic violence". The principle of omnia sunt interpretanda then becomes a manifestation of a new dimension of judicial independence, namely an independent authority over the meaning of legal text.

5. There is, not only in Poland but in the whole culture of the statutory law, a peculiar crisis of the possibilities for effective administration by means of law which is written in ethnic language and which consists of general and abstract rules. There is a crisis of the relations between law and law-making state, which manifests itself in the peculiar process of legal institutions becoming autonomous in relation to state institutions. Much of the normative acts, which are applied by the courts, do not derive from their state. In this context, the principle of omnia sunt interpretanda constitutes the manifestation of the way 
in which courts come up with a new definition of the role of the third power. The latter ceases to act as "an extended arm" of the sovereign, and it rather becomes the third power sui generic-equally independent from the legislative, just as the legislature from the executive or the executive from the judiciary and the legislative.

Though the above advantages are considerable, there is a danger that the principle of omnia sunt interpetanda, not supplemented with any specific interpretative procedure, will lead to the disintegration of the consistency of jurisdiction. Although it is increasingly common for the legal literature to refer to derivational conception of interpretation, it has not been yet assimilated by the practice. It puts high scientific demands for the interpreter and it is being very superficially referred to in the jurisdiction, it is often mostly confined to the application of the phrase "decoding" but without a deeper understanding of this concept. Sometimes one can encounter a mixture of the concepts of derivational and classificatory theories in one ruling. In time the level of knowledge on the theory of interpretation will undoubtedly be improved among practitioners but, so far, one can have the impression that the principle of omnia sunt interpretanda is left alone on the battlefield of the proper interpretation of law.

Can we therefore propose some remedial measures which-irrespective of the postulate of a wider use of the theory of interpretation by practitioners-will somehow prevent the effects of such interpreted self-empowerment of the principle of omnia sunt interpretanda in the Polish jurisdiction? This begs the thought that, since in practice there is a lack of good theoretical basis, the problem at issue should be considered in terms of organizing the process of interpretation. The latter does not obviously guarantee that specific outcomes of interpretation are bound to be achieved, but perhaps organizational requirements placed upon the courts could at least reduce the degree of inconsistency of the results of interpretation.

6. The most commonly used methods for achieving uniformity of jurisdiction is undeniably regular supervision of the courts of higher instance over the lower courts. Yet, the judiciary has long been familiar with other methods of organizing the process of interpretation, like expanding the panels of judges in cases which give rise to interpretative problems, giving their judgments greater validity and, what is particularly interesting, granting courts an abstract right to interpret legal provisions separately from the facts that a given case pertains to and giving special validity to such an interpretation. What can be recognized as a good example at this point is the Polish administrative judiciary, which at the level of the Supreme Administrative Court, oscillating between the concept of the state council and the concept of an administrative court, has been equipped with special powers of interpretation.

With regard to the resolutions of the Polish Supreme Administrative Court Act, the acts of law which reformed the administrative judiciary, have introduced since 2004 two categories of resolutions taken by the Supreme Administrative Court and they introduced a new way to regulate the binding nature of resolutions. 
Without going into details, it should be noted that article $15 \S 1$ point 2 and 3 of the Act on the proceedings before administrative courts of 30 August 2002 (Journal of Laws No. 153, item 1270, as amended) introduced two categories of resolutions: (a) abstract resolutions, (b) specific resolutions. In accordance with article $15 \S 1$ point 2 of the abovementioned Act, abstract resolutions are taken in order to clarify the legal provisions, the application of which caused discrepancies in the jurisdiction of administrative courts. Such resolutions therefore pertain to legal uncertainties, which have no direct connection with proceedings pending in the individual case before the administrative court. This category of resolutions was not known under previously binding provisions regulating the Supreme Administrative Court.

In turn, according to the article $15 \S 1$ point 3 of the Act on the proceedings before administrative courts, specific resolutions can have as their subject only such legal uncertainties that have occurred whilst hearing the cassation complaint, namely the ones that show a close connection with proceedings in the individual case pending before the Supreme Administrative Court.

Interpretative work and its strategies vary greatly depending on the type of a given resolution, because an abstract resolution is not connected to a specific case.

What seems crucial for the purposes of our discussion is the fact that both abstract as well as specific resolutions have been granted a general binding power with the effect from 1 January 2004, on the basis of article $269 \S 1$ of the Act on the proceedings before administrative courts. This provision formalized the mode allowing the panels of judges in the administrative courts to derogate from the position adopted in abstract or specific resolution. In accordance with article $269 \S 1$ of the Act on the proceedings before administrative courts, if any panel of the administrative court that hears a given case does not share the view expressed in the resolution of the Supreme Administrative Court, legal query arising in this way shall be presented to a relevant composition of this Court for adjudication. Moreover, if a composition of one Chamber of the Supreme Administrative Court that clarifies the legal issue does not share the view expressed in the resolution of another Chamber, then it submit this issue to the full bench of the Supreme Administrative Court for a resolution ( $\$ 3$ ). According to article $269 \S 1$ of the Act on the proceedings before administrative courts, all panels of administrative courts should adhere to such resolution. Although, there is a possibility of re-taking the resolution. The competence to initiate the re-taking can be exercise both by the Supreme Administrative Court bench and by panels of judges of the provincial administrative court. It should be stressed that such re-taking of the resolution is the only situation in which the adjudicating panel of the provincial administrative court can put forward the initiative of taking a resolution. This regulation lays grounds for the principle of all administrative courts being bound with a peculiar legal interpretation made in the resolution. The presentation of a legal query by the administrative court, as stipulated in the article $269 \S 1$ of the Act on the proceedings before administrative courts, results in the appropriate adjudicating panel of the Supreme Administrative 
Court re-taking the resolution. Pursuant to $\S 2$ of the abovementioned provision, in the course of this procedure, the Supreme Administrative Court cannot issue the ruling to refuse the answer. In the event the previous standpoint has been maintained in such resolution, the adjudicating panel of the administrative court will be bound thereby. However, in case of changing the previous standpoint expressed in the resolution, the "newly" issued resolution shall be granted a directly binding force in the case at hand as well as a generally binding force.

Although the provisions of court-administrative procedure do not govern the measures which force adjudicating panels to apply the procedure set forth in article 269 of the Act on the proceedings before administrative courts, it is assumed that if the adjudicating bench of the Supreme Administrative Court or a given provincial administrative court—when issuing a judgment—did not respect the interpretation presented in the resolution put forward by the Supreme Administrative Court in its resolution, by adopting a different interpretation of the legal issues and thus did not apply the procedure provided for in article 269 of the abovementioned Act, it would constitute a violation of this provision. The latter might therefore affect the outcome of the case, and might sometimes also constitute insult of substantive law, consisting of an erroneous interpretation of the provisions constituting the legal basis for judicial decision.

All means applied by the Polish legislature, like organizing the process of interpretation on the basis of expanding adjudicating panels of judges in cases that give rise to interpretative problems, granting them a greater binding power and, what is particularly interesting, granting courts the right to an abstract interpretation of legal provisions separately from the factual grounds that a given case pertains to and granting such an interpretation a special binding power-they all allow for a considerable unification of jurisdiction. Such organizational procedures alleviate the consequences of the principle of omnia sunt interpetanda without referring to any particular theory of interpretation, but in a purely formal manner that does not offer any qualitative criteria of interpretation and which, at the very most, increases coherence of jurisdiction.

7. Substantive impact on the interpretation is possible only when we attempt to organize a community of judges for the activities of legal interpretation undertaken by them. But there are no neutral criteria for assessing the effectiveness of such a community. Its assessment is dependent on the philosophical and legal views on the nature of such groups. The view on the nature of courts activity and hence the way in which judges exercise power has significantly evolved in the last century. The choice of adjudicating philosophy decides on the conception of organizing communities of judges. Let us now try to present the main philosophical and legal views on the optimal organization of judges as law-interpreting groups.

8. The relationship between the organization of courts and adjudicating is manifested mainly in the different ways of assessing lawyer's liability for the content of the applicable law. Changes postulated in lawyers' attitude to the process of law application in conjunction with the requirement that they shall 
explicitly assume liability for the content of law "clash" with the radical positivism which requires lawyers to adopt mainly cognitive attitude to law. It is a manifestation of a new, proactive vision of the law which begins to pave its way in the legal culture. For this reason, lawyers, and mostly judges, are often accused of violating the rules of professional ethics, since their lack of response to the shortcomings of law is understood as their evasion from a proper fulfilment of the tasks of exercising judiciary power that was entrusted to them.

Since we are interested in views on the essence of adjudication, we will limit our considerations to the impact of the idea of what law is and how it is cognizable on the perception of the lawyer's role in the legal culture.

9. The model of training judges is dominated by the positivist vision of law and the conception of the lawyer that derives from the latter. Although legal positivism is accused, particularly from the perspective of philosophy of natural law, of resulting in law being subordinate to the political phenomena due to a ban on evaluating law-professed by legal positivism, in fact the methodology of a lawyer's work which it had developed, is not disputed in principle [7].

Positivism-recognized as a method-offers a conviction of the autonomy of law and its independence from political and economic phenomena. Positivism also deserves credit for universalizing the conceptual apparatus of law and jurisprudence that is used by a lawyer. Positivist legal education has considerably shielded legal culture from the conviction-being in opposition to positivism - that the law is derived from ideology or economic and political phenomena. Positivism, at least in terms of methodology, developed a model of a lawyer which can be easily applied also in the conception of the state of law. While the abovementioned achievements of positivism are obvious, it has instilled among lawyers a simplified vision of the law which dominated the European legal culture. This version of positivism can be called a primordial legal positivism.

The latter shows law as a sovereign's order which a lawyer-due to a legal method-subjects only to the formal analysis and organizes it conceptually. The law, as the content of acts of the sovereign's will, becomes the subject of legal cognition.

The role of the lawyer in a primordial positivism involves only cognitive relationship. It defines a lawyer as a delegate of the sovereign [1]. Each legitimated use of this delegation must be based on the assumption that it is only treated as pursuing the command of the sovereign. Formal-dogmatic method linked with the code as an ideal regulation, excludes the lawyer's impact on cultural patterns associated with the law.

Lawyers' participation in culture is presented by primordial positivism primarily as finding the essence of law by means of the method provided to them by jurisprudence. Primordial positivism therefore presents understanding of law as a process based on scientific methods.

What is being emphasised in a scientifically grasped conception of understanding law is a radical separation of the subject and the object of cognition. 
A lawyer does not constitute law as an object of culture, but he assumes a rather passive attitude towards it, purely cognitive one, the same that is taken vis-à-vis natural objects. The fact of constituting law by establishing its importance in law-application process is simply being hidden by the primordial legal positivism. Positivism, in principle, therefore suggests the possibility of objective cognition of law.

10. Primordial positivism sets a very limited conception of lawyers' participation in the culture by means of their professional activities, yet it opens the field of controversy, independent of the argument of natural law. This discussion relates to the role of lawyers, rather than to the place of law in the culture.

The lawyer becomes subordinated to the sovereign - the legislator, whilst his work is based on a conviction of the existence of law as an object cognizable independently of the lawyer himself. Primordial positivism leads to the instrumentalization of the activities of adjudication.

In such an approach there is no room for the relations between the quality of the interpretation process with the way of organizing the judges. The organization of the courts is, in fact, determined only by political qualities of the third power. It consists in ensuring independence of judges and of courts as the third power, in order to enable them to search and systematize the patterns of behaviour contained in the text issued by the sovereign.

11. The necessity for legal reflection on the organization of judges was only created by Herbert L. A. Hart's positivism because it presents cognition of law not only as external cognition of the regularity of behaviour associated with the law, but also as capturing the so-called internal aspect of the rule, namely assuming "a critical—reflective attitude" towards the latter [3: 52]. Hart shows that it is only by the internal approach to the law that its normativity is revealed. Normativity does not merely boil down to a pattern of behaviour contained in the norm, to the contents of a sovereign act of will, but it is rather revealed in cognition as a certain meaning.

Turning to the analytical philosophy of language, Hart assumes that the essential feature of meaning is the fact that it cannot be captured directly as a natural object. This is the very thesis that his sophisticated positivism is based on. Hart repeals epistemological naivety of primordial positivism and, at the same time, he allows to distinguish normativity from ordinary habitual social rules.

The recognition and a new understanding of the role of language in adjudication allows ultimately to distinguish between the primordial and sophisticated positivism. Primordial positivism ignores the phenomenon of presenting adjudication by means of the language. Sophisticated positivism introduces the so-called internal point of view, thus introducing to positivism the problem of hermeneutics, namely understanding law.

Recognition of the rule only as a stimulus is differentiated from its understanding. The rule is not law until its addressee assumes a certain attitude to it, which Hart referred to as critical—reflective one which means roughly that the addressee accepts it or makes such arguments which seek to 
justify its specific meaning. This meaning is never given directly, but it is revealed in the process of argumentation.

12. Since Hart has shown that a lawyer always perceives participation in culture as a reflective participation in a given linguistic community, his conception entails a change of the essence of adjudication and interpretation. Despite the fact that also in this version of positivism, the role of a lawyer is limited merely to cognition of the law, the latter is presented as a process controlled by the linguistic community of judges. The content of the law is determined by the existence of a certain social argumentative convention of recognizing norms as the norms of binding law (the rule of recognition).

The nature of adjudicating does not undergo any fundamental change, because it still consists in cognition of law-yet-what does changes it is the conception of the structure of epistemology of law and this structure affects the organization of courts. Courts cannot be organized in such way as to merely ensure proper relations between the judge and the sovereign. Cognition of law always takes place by means of language, and therefore the court must be managed in such way as to form a linguistic community of judges, because it is only in the process of social communication that the cognition of the text of law becomes possible.

Even in its sophisticated version, however, positivism, preserves a limited social role of such communities, it protects judges from the requirement of activism. This is best manifested in interpretative analysis of judicial decision. Perceiving the problem of the so-called open textuality which generates a certain degree of discretion, Hart denies the existence of the standard of a "correct" judicial decision [3: 135]. A very narrow approach to the role of the lawyer in the culture, reduced to cognition of the law in a certain linguistic community, at the same time causes that in the so-called hard cases, judges have to seek settlement outside the law and act as delegates of the sovereign [3: 141]. As a specific judicial community, therefore, judges cannot reveal their beliefs.

The judge is not able to actively influence the content of the rules, thereby creating the antinomy inherent for positivist vision of the legal culture. Enriching epistemology of law with linguistic problems, on the one hand, draws attention to the discretion of judicial decisions and, on the other hand, prevents from adopting the conception of the legal culture which approves the fact that lawyers introduce solutions being the result of their own activity. In this situation, it is only by reference to the authority of the court, which has its source in the sovereign's delegation, that Hart tries to save the rationality of the conception of legal culture as outlined above. The procedure of introducing linguistic categories, and especially the conception of open textuality, reveals inconsistencies of sophisticated positivism.

13. Both the primordial as well as sophisticated positivism preserve the conviction of the conventional nature of the judge's cognitive acts. A lawyer in the process of cognition of law is confined to specific patterns imposed on him by the legal culture. Adjudication in a primordial case is based on the political convention, whilst in the second one-on the convention adopted by the linguistic community of judges. 
The conception of legal culture resulting from a sophisticated legal positivism preserves, therefore, judges' limited participation in culture, and thus the very process of adjudication itself - as the primary role of the judge.

In positivist approach, participation in culture via law takes place primarily in the process of cognition of law. The law, presented as an object of cognition separated from the subject that ascertains it, must be sufficiently "objectivised" either by a political convention that refers to the constraint (Austin), or by linguistic-argumentative one (Hart).

For this reason, the basic problem in positivism is removing subjective elements from the act of cognition. Maintaining the boundary between subjectivity and objectivity in the cognition of law is one of the foundations of positivist epistemology [10].

Hart does not substantially alter this conception of adjudication, although positivism in his approach is enriched with the so-called internal point of view and the linguistic concept of legal language. Adjudication still consists in cognition of law, reading its provisions without the possibility of substantially influencing actual cultural patterns. Sophisticated positivism, however, autonomizes the process of adjudicating. It rejects the argument that adjudication is a process that can be reduced to other cultural patterns, such as political or economic ones. Adjudication, as an autonomous cultural activity, is characterized by its independence of law from politics, by legitimizing state power by means of law, by the control of coercion and its restriction, by acceptance of pluralism of moralities which form axiological background of law, by the existence of the test of the legality of acts of making and applying law and by justifying legal decisions on the basis of formal compliance with the law [8].

What becomes the essence of adjudicating in a sophisticated positivism is creating a normative sense by judges. Primordial positivism does not find the independence of linguistic mediation of law, assuming that the content of the law is ascertained only through linguistic correctness of the text, which provides - to a significant extent-the possibility of reading it in a manner consistent with the legislator's intention.

14. The primordial legal positivism based the construction of law on the reduction of positivist law to the tacit command of the sovereign. Legal norm is presented in this approach as a phenomenon obtained by an external observation of social activity and its response to the activities of the sovereign. Although sophisticated positivism (Hart) separates the validity of the norm from the responses to the latter, it still remains a social theory of law (descriptive sociology). What does change, however, is the scope of the social dimension of law. Normativity does not merely come down to the pattern of behaviour contained in the norm, to the content of a sovereign act of will, but it is revealed in cognition as certain meaning. The essential feature of the meaning is the fact that it cannot be captured directly as a natural object.

The sovereign's act of will is not recognized in the social relation of a direct subordination to the sovereign, but it is rather perceived as a meaning created by a certain type of communities, namely judicial linguistic communities. 
Their role is reduced, however, only to enabling its members to properly identify and capture speech acts, as they proceed in social life, thus they only prevent linguistic alienation of the judges in the process of interpretation.

Yet, even in a sophisticated positivism, the cognitive relation between subject and object remains undisputed. Law is recognized as an object separate from the subject, since in order to ascertain law via language, it is sufficient if the subject meets certain conventional social criteria for the recognition of a given rules as law.

What is also assumed here is a certain model of dogmas and theory of law, which involves the juxtaposition of the examined object and examining subject, giving the illusion that there exists "a primordial point", a certain proper text being a point of departure in legal argumentation [12]. What is being hidden is the fact that the law cannot be seen solely as an object developed as a result of a deliberate and conscious creation of law, but also as a specific result of acts of communication.

The view on adjudication undergoes a transformation on the basis of sophisticated positivism. Adjudication and the process of interpretationincluded in the latter-is based on two relations: a judge vis-à-vis the sovereign and a judge vis-à-vis the language as a mediation of the sovereign's acts of will. As indicated above, the organization of courts must allow the realization of these two relations.

The ideal organization of the court refers still to a relative isolationism. Judicial communities of communication affect the society and its goals just by participating in acts of speech. There is, however, no room for active adjudication in which judges become fully-fledged active participants in cultural communication.

15. It is only an integrative conception of adjudication that perceives such a broad conception of adjudication, making adjudication and the results of interpretation one of the main mechanisms for integrating normativity of culture. According to Ronald Dworkin, the entire effort of jurisprudence should be geared to adjudication and interpretation, since it is a problem that permeates the law and its institutions. What is crucial for the lawyer is only such a general reflection on the law which allows the judge to make a better judgment on the basis of law. The central point in a general reflection on the law-so important for lawyers - is adjudication, being the activity which enables to give the best sense to law as a kind of peculiar social practice.

Yet, adjudication cannot be reduced to the description of law or definition of its concept. Neither can it come down to giving meanings to law by a linguistic community of judges, isolated from social practices.

By introducing the category of legal principles to adjudication, Dworkin makes them a factor that integrates culture. Adjudication becomes primarily an integrative interpretation. At the same time, however, it appears that interpretation, albeit within certain limits, must be of a creative nature. As we know, the rules are not merely applied but they are "weighted". The task of the practice of law and jurisprudence is precisely to achieve the integration of the whole normative social structure, one part of which only consists of legal rules. 
Interpretative jurisprudence considers that the role of judges and jurisprudence is the search for the best understanding of the law in the context of norms and the value of culture [2: 410-411]. According to Dworkin, an apt metaphor is the one that compares the constitution of law to a common creation of a novel by generations of authors who add subsequent chapters to the text.

In this way, the judiciary becomes a reality, since by means of adjudication, judges have power over the integration of normative meanings in culture.

Due to discursivity of law, even in situations of ambiguous legal norms, by means of normative context of social life, the rights of parties are included in the law, though not directly. The judge does not build a normative sense when describing an object that exists objectively as law. The law is not ready or complete for a judge when the legislator formulates it. Pursuant to integrative theory, the judge formulates arguments that support the claims about the rights and obligations of legal subjects.

It is not necessary for a judge, therefore, to stand for the majority, because he is a fully-fledged participant of argumentation who has the right to issue the judgment. Accordingly, he is not only a representative of a democratic sovereign. As a participant of the judicial practice, he does not formulate descriptive statements about the law, he formulates them as a participant of culture, normatively involved in the expressions concerning the rights and obligations. He does not need to embrace the popular view, the view of the majority. On the basis of integrative theory of jurisdiction it is possible for the judge to reject the view expressed by the majority in the situation of ambiguous law.

Cognition of the law does not begin-contrary to the tradition of legal positivism - from some original starting point which allows cognition by means of the test of the origin of law. By argumentation, it determines the subjective rights of the parties, taking into consideration moral traditions of society. It is therefore axiologically involved. According to Dworkin, there is no neutral, starting moment of capturing law as an object of cognition and, therefore, one should reject the so-called semantic approach to the law.

16. Adjudicating in the situation of discretion is not based on the representation of the sovereign, because the semantics created by the sovereign does not constitute the essence of law.

Proper cognition of the law is achieved by integrating a judicial decision, understood by Dworkin as a decision complying with the whole legal tradition, while at the same time this decision is based on the most reasonable interpretation of that tradition [2: 176-275]. It is neither a mere recognition of the past, nor mere debate of the purpose that a given community aims at.

Legal integrity demands from a judge that he should-as far as it is only possible-assume in his adjudication that the structure of the law is constituted by a coherent set of principles relating to justice, fairness and due process [2: 243]. Legal integrity is not achieved through merely linguistic consistency of judicial community of communication.

The novelty of this conception of law is a vision of adjudication as a mechanism which enables negotiations between the various spheres of social 
normativity. What becomes the essence of adjudication then is the judge's relation to culture which is to achieve integrity due to adjudication.

17. The organization of the courts must therefore enable "opening" of adjudication process, granting the judge the access to the whole normativity of a given community. The court shall cease to be a closed, mysterious castle of judges, it should become the "capital of law" [2: 407].

In such conception there is room for an open organization of the courts, the opposite of which is positivist isolationism of judges. The main tool for adjudication consists in "constructive interpretation". It is based on politically most acceptable validation of a certain tradition, contained in the available legal material from the past.

The essence of good organization of the court does not consist in allowing the internal group communication among judges, but it should lead to a constructive adjudication, understood by Dworkin as a judgment imposing certain objectives that integrate social practices [2: 52].

When speaking about the types of communities, Dworkin describes, inter alia, the type of community of rules and community of principles [2: 209-215]. Members of the community of rules determine the principles of activities that cover the content of their mutual commitments. What they want in fact is to fairly and honestly agree on the conception of justice and fairness and to express it in the rules formulated as a result of negotiation and compromise. These rules are conventional in nature, because they result only from reciprocal arrangements. Such a group is dominated by legalism, and rules are complied with, until they are amended.

Community of principles is also based on the agreement. However, the basis of the agreement is not only a convention of negotiated rules, but the belief in the acceptance of common values and principles that integrate the community. In such a community, therefore, there is room for a permanent debate, not on the meaning of the "rules", but on the understanding of the principles that the community should accept. Judges can be perceived as a community of constant debate about justice, fairness and procedural reliability, because these values are not treated as something previously granted, but as beliefs which integrate the community. Permanent deliberation on these values in the changing circumstances, is understood as a discussion that maintains continuous involvement in the history and in the future of the community.

It could be then postulated that integrative judiciary strives to create judicial community of principles. It is not only the protection of the independence, the study of conventions of language which expresses the law but, above all, creating a mechanism of judicial deliberation on the law as a factor integrating social normativities that becomes the main objective of judicial governability.

18. Judicial organization of interpretation process is a means of saving the unity of interpretation in the situation when practice does not make use of a good theoretical background. Proper organization of the judiciary prevents a peculiar development of anarchy in the realm of interpretative practice. The Polish legislator organizes the process of interpretation by extending adjudicating panels in cases which might give rise to interpretative problems 
and by granting a greater binding power to judicial decisions. What is particularly interesting is the fact that some courts are granted the right to abstract interpretation of legal provisions in isolation from the factual grounds at issue and special binding power is granted to such an interpretation.

This type of organizational procedures alleviate the problem of inconsistency of the jurisdiction, but in a purely formal manner which does not offer any qualitative criteria of interpretation and which only increases cohesion of the jurisdiction. Qualitative impact on the interpretation is possible only when we are trying to organize the very community of judges for the purpose of fulfilling its role consisting in law interpretation. What can be pointed out with certainty are three groups of such criteria, offering various ideals of the judiciary. Their evaluation is dependent on the philosophical and legal views on the nature of the court's role in social life. As shown by the abovementioned considerations, there are no neutral, purely praxeological criteria for assessing the effectiveness of such a community.

Open Access This article is distributed under the terms of the Creative Commons Attribution Noncommercial License which permits any noncommercial use, distribution, and reproduction in any medium, provided the original author(s) and source are credited.

\section{References}

1. Cotterrell, Roger. 1989. The politics of jurisprudence. London and Edinburgh: Oxford University Press, 75ff.

2. Dworkin, Ronald. 1986. Law's empire. London: Fontana Press, 410-411, 176-275, 243, 407, 52, 209-215.

3. Hart Herbert, L. A. 1961. The concept of law. Oxford: Oxford University Press, 52, 135, 141.

4. Kennedy, Duncan. 1979. The structure of blackstone's commentaries. Buffalo Law Review 28: 213.

5. Kubiak, Renata, ed. 2006. Prawo-wtadza—spoteczeństwo-polityka. Księga jubileuszowa profesora Krzysztofa Pateckiego [Law-Power-Society-Politics. The jubilee book of professor Krzysztof Pałecki]. Toruń: Adam Marszałek Publishing House. These judgments are quoted in details on a 67.

6. Lucy, William. 1999. Understanding and explaining adjudication. Oxford: Oxford University Press, $1,7,7$.

7. Morawski, Lech. 2004. Wstęp do prawoznawstwa [Introduction to Jurisprudence]. Toruń: TNOIK, $10 \mathrm{ff}$.

8. Nonet, Philippe, and Philip Selznick. 1978. Law and society in transition. Towards responsive law. New York: Harper Torch Books.

9. Zieliński, Maciej. 2002. Wyktadnia prawa. Zasady, Reguty, Wskazówki [Interpretation of law, principles, rules, guidance], Warszawa: LexisNexis.

10. Zirk-Sadowski, Marek. 2004. Legal epistemology and transformation of legal cultures. In Epistemology and methodology of comparative law, ed. van Hoecke Mark, 21-35. London: Hart Publishing.

11. Zirk-Sadowski, Marek. 2008. Post-modern jurisprudence? In Politics of law and legal policy. Between modern and post-modern jurisprudence, ed. Biernat, Tadeusz and Zirk-Sadowski Marek, 343-359. Warszawa: Wolter Kluwer.

12. Zirk-Sadowski, Marek. 2001. Pozytywizm prawniczy a filozoficzna opozycja podmiotu i przedmiotu poznania [Legal positivism and philosophical opposition of the subject and object of cognition]. In Studia z filozofii prawa [Studies in philosophy of law], ed. Stelmach, Jerzy. Kraków: Wydawnictwo Uniwersytet Jagielloński. 